\title{
Dietary patterns among Norwegian 2-year-olds in 1999 and in 2007 and associations with child and parent characteristics
}

\author{
Anne Lene Kristiansen ${ }^{1 *}$, Britt Lande ${ }^{2}$, Joseph Andrew Sexton ${ }^{3}$ and Lene Frost Andersen ${ }^{1}$ \\ ${ }^{1}$ Department of Nutrition, Institute of Basic Medical Sciences, University of Oslo, PO Box 1046, Blindern, O316 Oslo, Norway \\ ${ }^{2}$ Division of Public Health, Norwegian Directorate of Health, Oslo, Norway \\ ${ }^{3}$ Department of Biostatistics, Institute of Basic Medical Sciences, University of Oslo, Norway \\ (Submitted 1 February 2012 - Final revision received 24 August 2012 - Accepted 10 September 2012 - First published online 29 November 2012)
}

\section{Abstract}

Infant and childhood nutrition influences short- and long-term health. The objective of the present paper has been to explore dietary patterns and their associations with child and parent characteristics at two time points. Parents of Norwegian 2-year-olds were, in 1999 ( $n$ 3000) and in 2007 ( $n$ 2984), invited to participate in a national dietary survey. At both time points, diet was assessed by a semiquantitative FFQ that also provided information on several child and parent characteristics. A total of 1373 participants in the 1999 sample and 1472 participants in the 2007 sample were included in the analyses. Dietary patterns were identified by principal components analysis and related to child and parent characteristics using the general linear model. Four dietary patterns were identified at each time point. The 'unhealthy' and 'healthy' patterns in 1999 and 2007 showed similarities with regard to loadings of food groups. Both the 'bread and spread-based' pattern in 1999 and the 'traditional' pattern in 2007 had high positive loadings for bread and spreads; however, the 'traditional' pattern did also include positive associations with a warm meal. The last patterns identified in 1999 and in 2007 were not comparable with regard to loadings of food groups. All dietary patterns were significantly associated with one or several child and parent characteristics. In conclusion, the 'unhealthy' patterns in 1999 and in 2007 showed similarities with regard to loadings of food groups and were, at both time points, associated with sex, breastfeeding at 12 months of age, parity, maternal age and maternal work situation.

Key words: Principal components analysis: Dietary patterns: Preschool children: Norway

Infant and childhood nutrition influences short- and long-term health. For example, breastfeeding has been associated with a reduced risk of overweight and obesity later in life ${ }^{(1)}$. Furthermore, it has been found that health behaviours established early in life, such as dietary patterns, may persist over time $^{(2,3)}$. Associations between diet and health have traditionally been examined through exploring the relationship between a disease and a single or a few nutrients or food groups ${ }^{(4)}$. However, as foods are consumed in combinations and consist of a variety of nutrients, it is challenging to evaluate the role of individual nutrients or food groups in isolation ${ }^{(4,5)}$. A complementary approach to more traditional analyses is to analyse dietary patterns. Dietary patterns may be defined theoretically, empirically or using a combination of these two methods ${ }^{(5,6)}$. In a theoretical approach, nutrients and/or foods are grouped according to present nutritional knowledge (a priori methods) like diet indexes or scores. In an empirical approach, nutrients and/or foods are reduced into a smaller number of variables through statistical methods (data-driven methods) such as principal components analysis (PCA) or cluster analysis. A third option is a combination of the $a$ priori approach and the data-driven approach such as reduced rank regression ${ }^{(4,5)}$. Interestingly, it has been found that 'healthy' dietary patterns (derived using a data-driven approach) are consistent with diets that would score high on a healthy eating index (theoretically derived) ${ }^{(7)}$. In addition, similarities have also been found between dietary patterns derived by PCA and cluster analysis ${ }^{(8)}$

Knowledge of associations between dietary patterns and socio-demographic characteristics is important when developing strategies for promotion of healthier dietary habits among preschool children. There is limited information on dietary patterns and associations between dietary patterns and socio-demographic characteristics among preschool children. A review by Smithers et $a l{ }^{(7)}$ identified fourteen papers using PCA to derive dietary patterns, and only six of these reported relationships between dietary patterns and sociodemographic characteristics ${ }^{(3,9-13)}$. Information about dietary patterns among Norwegian preschool children is scarce.

Abbreviations: ALSPAC, Avon Longitudinal Study of Parents and Children; MoBa, Norwegian Mother and Child Cohort Study; PCA, principal components analysis; SFFQ, semi-quantitative FFQ.

*Corresponding author: A. L. Kristiansen, email a.l.kristiansen@medisin.uio.no 
Based on data from two large national dietary surveys among the Norwegian 2-year-olds in $1999^{(14)}$ and in $2007^{(15)}$, the present study explores dietary patterns, identified by PCA at two time points, and investigates their association with sociodemographic characteristics as well as other relevant child and parent characteristics.

\section{Materials and methods}

\section{Subjects}

In 1999 and 2007, Statistics Norway established samples of 3000 and 2984 Norwegian 2-year-olds, respectively. The samples in 1999 and in 2007 included all children born in Norway during a 3-week period in March 1997 and in September 2005, respectively, to mothers born in Norway, Sweden or Denmark. If the child was a twin or a triplet, the mothers/parents were asked only to include the oldest. Informed consent was obtained from the mothers/parents. Those who gave a written refusal to participate were not contacted any further. In 1999, the sample consisted of 1720 children ( $57 \%$ response rate), while the sample in 2007 consisted of 1674 children (56\% response rate). The present study was conducted according to the guidelines laid down in the Declaration of Helsinki, and all procedures involving human subjects were approved by the Regional Committees for Medical Research Ethics.

\section{Design}

A similar study design was used in 1999 and in 2007. The 1999 study was carried out in February-July, while the 2007 study was carried out in August-October. The mothers/parents received an invitation letter and a semi-quantitative FFQ (SFFQ) by mail, about 2 weeks before the child turned 2 years. In 1999, the mothers/parents received one combined thanks/ reminder letter and one reminder with the questionnaire enclosed. In 2007, the mothers/parents were contacted once by telephone and received one reminder with the questionnaire enclosed. Those who returned a completed questionnaire were entered in a lottery. In addition, all who returned a completed questionnaire in 2007 received a recipe book.

\section{Semi-quantitative FFQ}

At both time points, diet was assessed with a SFFQ: in 1999 the SFFQ-1999 and in 2007 the SFFQ-2007. Mothers/parents were asked to complete the questionnaires as closely as possible to the child's second birthday. They were asked to keep the last $14 \mathrm{~d}$ in mind when filling in the questionnaire. Both questionnaires had been tested in pilot studies and subsequently revised; furthermore, the SFFQ-1999 and the SFFQ-2007 had been validated against $7^{(16)}$ and $4 \mathrm{~d}$ weighed records, respectively $^{(17)}$. The SFFQ-1999 and the SFFQ-2007 and the differences between them are described in more detail elsewhere $^{(14,15,18)}$.

In brief, the SFFQ included questions about a wide range of food items grouped together according to the Norwegian meal pattern. The frequency alternatives varied from never/less than once per month to several times per $d$, the number of frequencies' alternatives (including the frequency 'never/less than') varied from five to eight in the two questionnaires. A photographic booklet including more than fifteen series of colour photographs with four differently sized portions ranging from small (A) to large (D) was used by the parents when reporting the amounts of food eaten. When no photograph was available for a food item, household units were used, e.g. slices, pieces and spoons. Compared with the SFFQ-1999, slight modifications were made to the range of frequency alternatives, some of the frequency options and the photographic booklet in the SFFQ- $2007^{(18)}$.

In the present study, food items were combined into food groups based on characteristics of the diet among preschool children and merging of similar food items (both according to type of food items and nutrient content). For example, all types of cheese/cheese spreads were merged into one food group labelled 'cheese' (Table S1, available online). Food groups were created as similar as possible to ensure comparability of the dietary patterns obtained in 1999 and 2007. The main questions on food items were the same in both surveys; however, the SFFQ-1999 included questions on 131 food items, while the SFFQ-2007 included 151 food items. Intake of dietary supplements was not included in the PCA analysis. Portion sizes were the same for most food items at both time points, and food intakes reported in both questionnaires were converted to daily intakes $(\mathrm{g} / \mathrm{d})$. A total of forty-six and forty-seven non-overlapping food groups were created for the SFFQ-1999 and the SFFQ-2007, respectively (Table S1, available online). The food groups entered into PCA were in general normally distributed.

\section{Child and parent characteristics}

In both surveys, several child and parent characteristics were collected. These mainly concerned socio-demographic characteristics, but other characteristics, such as breastfeeding at 12 months of age and maternal smoking, were also included. In 1999, Statistics Norway provided information on the sex of each child, while in 2007 this was asked for in the SFFQ. Breastfeeding was reported in the SFFQ as how old (in weeks from birth to 7 weeks and in months from 2 to 24 months) the child was when breastfeeding was ceased. Breastfeeding at 12 months of age was categorised as yes (breastfeeding for 12 completed months) and no. The parity of the mother was categorised into three groups: one child, two children and three or more children. In 1999, Statistics Norway provided information on maternal age when the child was 2 years of age, while this was asked for in the SFFQ-2007. Maternal age, reported as a continuous variable, was categorised into $\leq 24,25-34$ and $\geq 35$ years. Maternal marital status was coded as married/cohabitant and not married/ cohabitant. A total of ten categories of maternal work situation, when the child was 2 years of age, were combined into four categories: full time, part time, on leave and others (including mothers working at home/housewives, mothers on sick leave, unemployed, disabled, occupational rehabilitation, student or other work situations). Maternal and paternal 
educational levels were in the SFFQ-1999 and the SFFQ-2007 coded by seven and eight categories, respectively. For both questionnaires, the educational levels were combined into three categories: primary/secondary/comprehensive school, academy/college/university of $\leq 4$ years and academy/ college/university $>4$ years. In 2007, maternal smoking status was coded as smoker and non-smoker. The SFFQ-1999 did not elicit maternal smoking status. Geographical region was divided into six categories in both surveys: Capital and surroundings, East, South, West, Middle and North regions.

\section{Statistical methods}

Extraction of dietary patterns. To identify major dietary patterns among 2-year-olds, PCA was performed on the forty-six and forty-seven food groups obtained from the SFFQ-1999 and the SFFQ-2007, respectively. The analysis was conducted separately for each study year. Prior to conducting PCA, the suitability of the data for such analysis was assessed. The Kaiser-Meyer-Olkin statistic was 0.67 at both time points and greater than the cut-off value of $0.6^{(19)}$. Moreover, at both time points, Barlett's test of sphericity was significant $(P<0.001)$, supporting the suitability of the data for PCA. PCA is a data reduction technique, and aggregates food groups on the basis of the degree to which they correlate with one another (i.e. 'found to be consumed together in diet assessments') ${ }^{(5)}$. A challenging decision is to select the number of dietary patterns that best represent the data. One way of deciding this is by determining the break point in the scree plot ${ }^{(5)}$. However, this was inconclusive at both time points. Therefore, the number of dietary patterns was chosen primarily on the basis of the eigenvalue (explained variance). At both time points, the first four dietary patterns had reasonable interpretations and were chosen for further analysis. These four dietary patterns accounted for $20 \%$ of the total variance at both time points. The remaining dietary patterns all had eigenvalues less than $1 \cdot 6$, and thus individually explained only a small fraction of the overall variance in the data.

To improve the interpretation of the dietary patterns, the four-factor solution was rotated by orthogonal (varimax) rotation. The varimax rotation method leads to large loadings on a few variables and small (or zero) loadings on the remaining variables. Output from the PCA analysis includes factor loadings for each food group within each dietary pattern, which can be understood as correlation coefficients. Although all loadings have been reported, the labelling of the dietary patterns was based on the type of food groups that loaded most heavily on each pattern. Food groups were considered to be heavily loaded on a dietary pattern if they had factor loadings $\geq 0 \cdot 3$. For each child, a score was created for each of the four dietary patterns. Each score has a mean of 0 , and a high score indicates that a child's diet is more strongly associated with the corresponding dietary pattern.

Analysis of associations. The general linear model was used to explore if characteristics of the children and their parents were associated with the dietary patterns. A general linear model was formed for each dietary pattern, treating the corresponding scores as the dependent variable. The anal- ysis was conducted separately for each study year. Included in the model were all characteristics of the children and their parents, as presented in Table 1, with the exception of maternal smoking, which was only available for the 2007 data. $P$ values less than 0.05 were considered statistically significant. All statistical analyses were performed by IBM $^{\circledR}$ SPSS ${ }^{\circledR}$ Statistics, version 18.0 (IBM Corporation).

\section{Results}

Of the 1720 questionnaires returned in 1999, 1373 (80\%) had complete data on all characteristics. In the 2007 sample, 1472 out of 1674 (88\%) were complete. The analysis was based on complete cases. Table 1 presents the characteristics of the children and their parents. The participants in the 2007 survey differed from those in the 1999 survey in the following ways: parity was lower $(P=0 \cdot 011)$ and maternal age greater $(P=0.000)$, and both maternal education $(P=0.000)$ and paternal education $(P=0.049)$ were higher. In addition, there were differences according to maternal work situation, where more mothers worked full time and fewer were in the category 'other' in the 2007 survey compared with the 1999 survey.

Tables 2 and 3 summarise the dietary patterns extracted by PCA for the 1999 and the 2007 data, respectively. The dietary patterns are listed in the order they were extracted with their explained variance.

The 'unhealthy' pattern was, across time, characterised by food groups, with high loadings for sweet and salty snacks, ice-cream and puddings, sugar-sweetened drinks, hamburger buns, cakes and biscuits, fried potatoes, ketchup and pizza. This pattern explained 5.7 and $5.6 \%$ of the variance in 1999 and 2007 , respectively. At both time points, a type of healthy pattern was observed, which had high loadings for vegetables, pasta, rice, fish, poultry, water, fruits and berries. In 2007, high loadings were also observed for tomato soup/other soup, pancakes, pizza and cakes and biscuits, which are not readily associated with a healthy pattern. In 1999 this pattern accounted for $5.6 \%$ of the variance, while $4.7 \%$ of the variance was explained in the 2007 data. The bread and spread-based' pattern in 1999 (5.4\% variance) had high loadings for semi- and whole-grain bread, butter/margarine, meat, cheese and sweet spreads, and high negative loadings for porridge and unsweetened cereals. The 'traditional pattern in 2007 ( $5 \cdot 1 \%$ variance) was characterised by high loadings for meat, potatoes, sauce, butter/margarine, semi- and wholegrain bread, fish, eggs, vegetables, stew with meat, vegetables and potatoes. The 'baby food' pattern in 2007 ( $4 \cdot 2 \%$ variance) was characterised by high loadings for porridge and unsweetened cereals, commercial baby food and sugar, and high negative loadings for semi- and whole-grain bread and cheese. Finally, the 'low-fat milk, pancakes, fruits and berries' pattern in 1999 (3.7\% variance) was characterised by high loadings for low-fat milk, pancakes, fruits and berries, including high negative loadings for full-fat milk.

Tables 4 and 5 present adjusted mean scores for each dietary pattern and their associations with the child and parental characteristics. All dietary patterns were significantly associated with one or more of the characteristics. 
Table 1. Characteristics of the children and their parents

(Number of subjects and percentages)

\begin{tabular}{|c|c|c|c|c|c|}
\hline \multirow[b]{2}{*}{ Characteristics } & \multicolumn{2}{|c|}{$\begin{array}{c}1999 \text { data } \\
(n \text { 1373) }\end{array}$} & \multicolumn{2}{|c|}{$\begin{array}{c}2007 \text { data } \\
(n 1472)\end{array}$} & \multirow[b]{2}{*}{$P^{*}$} \\
\hline & $n$ & $\%$ & $n$ & $\%$ & \\
\hline \multicolumn{6}{|l|}{ Sex } \\
\hline Boys & 687 & 50 & 718 & 49 & \multirow[t]{2}{*}{0.502} \\
\hline Girls & 686 & 50 & 754 & 51 & \\
\hline \multicolumn{6}{|l|}{ Breastfed at 12 months of age } \\
\hline No & 929 & 68 & 1018 & 72 & \multirow[t]{2}{*}{0.391} \\
\hline Yes & 444 & 32 & 454 & 28 & \\
\hline \multicolumn{6}{|l|}{ Parity } \\
\hline One child & 447 & 33 & 553 & 38 & \multirow[t]{3}{*}{0.011} \\
\hline Two children & 575 & 42 & 593 & 40 & \\
\hline$\geq$ Three children & 351 & 25 & 326 & 22 & \\
\hline \multicolumn{6}{|l|}{ Maternal age } \\
\hline$\leq 24$ years & 114 & 8 & 80 & 5 & \multirow[t]{3}{*}{0.000} \\
\hline $25-34$ years & 971 & 71 & 906 & 62 & \\
\hline$\geq 35$ years & 288 & 21 & 486 & 33 & \\
\hline \multicolumn{6}{|l|}{ Maternal marital status } \\
\hline Married/cohabitant & 1316 & 96 & 1419 & 96 & \multirow[t]{2}{*}{0.446} \\
\hline Not married/cohabitant & 57 & 4 & 53 & 4 & \\
\hline \multicolumn{6}{|l|}{ Maternal work situation now } \\
\hline Full time & 386 & 28 & 623 & 42 & \multirow{4}{*}{0.000} \\
\hline Part time & 448 & 33 & 432 & 29 & \\
\hline On leave & 141 & 10 & 155 & 11 & \\
\hline Other† & 398 & 29 & 262 & 18 & \\
\hline \multicolumn{6}{|l|}{ Maternal smoking } \\
\hline Non-smoker & \multirow{2}{*}{\multicolumn{2}{|c|}{ No data }} & 1207 & 82 & \\
\hline Smoker & & & 265 & 18 & \\
\hline \multicolumn{6}{|l|}{ Maternal education } \\
\hline Primary, secondary school and comprehensive school & 681 & 50 & 534 & 36 & \multirow{3}{*}{0.000} \\
\hline Academy/college/university ( $\leq 4$ years) & 461 & 33 & 530 & 36 & \\
\hline Academy/college/university ( $>4$ years) & 231 & 17 & 408 & 28 & \\
\hline \multicolumn{6}{|l|}{ Paternal education } \\
\hline Primary, secondary school and comprehensive school & 744 & 54 & 754 & 51 & \multirow{3}{*}{0.049} \\
\hline Academy/college/university ( $\leq 4$ years) & 339 & 25 & 350 & 24 & \\
\hline Academy/college/university ( $>4$ years) & 290 & 21 & 368 & 25 & \\
\hline \multicolumn{6}{|l|}{ Geographical region } \\
\hline Capital and surroundings & 278 & 20 & 365 & 25 & \multirow{6}{*}{0.070} \\
\hline East & 369 & 27 & 357 & 24 & \\
\hline South & 206 & 15 & 207 & 14 & \\
\hline West & 256 & 19 & 275 & 19 & \\
\hline Middle & 124 & 9 & 138 & 9 & \\
\hline North & 140 & 10 & 134 & 9 & \\
\hline
\end{tabular}

Girls had significantly lower mean scores than boys on all dietary patterns in the 1999 sample. In the 2007 data, this was the case for the 'unhealthy' and the 'traditional' patterns.

Children breastfed at 12 months of age had, at both time points, a significantly lower mean score for the 'unhealthy' pattern compared with those breastfed for less than 12 months.

In both 1999 and 2007, significantly higher, and increasing, mean scores for the 'unhealthy' pattern were seen for the 2-year-olds of mothers with two or more children, compared with mothers with one child. A similar association was observed for the 'low-fat milk, pancakes, fruits and berries' pattern in 1999. Having more than one child was associated with a significantly higher mean score for the 'bread and spread-based' pattern in 1999 and a significantly lower mean score for the 'baby food' pattern in 2007.
Increasing maternal age was associated with a significant reduction in the mean score for the 'unhealthy' pattern in 1999 and in 2007. This was also seen for the 'bread and spread-based' pattern in 1999, while the mean score for the 'baby food' pattern in 2007 increased with increasing maternal age.

Maternal work situation was significantly associated with the 'unhealthy' pattern at both time points, the 'bread and spread-based' pattern in 1999 and the 'baby food' pattern in 2007. Compared with all other work situations, the highest score for the 'bread and spread-based' pattern in 1999 was seen among the 2-year-olds of mothers working full time; the highest score for the 'baby food' pattern in 2007 was found among the 2-year-olds whose mothers were on leave. For the 'unhealthy' patterns at the two time points, the 
Table 2. Factor loadings of food groups in the four dietary patterns identified, together with the explained variance in percentage, in 2-year-old children in the 1999 data $(n$ 1373)

\begin{tabular}{|c|c|c|c|c|}
\hline & $\begin{array}{c}\text { Unhealthy } \\
5.7 \%\end{array}$ & $\begin{array}{l}\text { Healthy } \\
5.6 \%\end{array}$ & $\begin{array}{l}\text { Bread and spread-based } \\
5.4 \%\end{array}$ & $\begin{array}{c}\text { Low-fat milk, pancakes, } \\
\text { fruits and berries } \\
3.7 \%\end{array}$ \\
\hline Full-fat milk & 0.049 & 0.178 & -0.177 & $-0.570^{\star}$ \\
\hline Low-fat milk & -0.115 & -0.082 & 0.173 & $0.535^{\star}$ \\
\hline Chocolate milk & 0.285 & -0.074 & -0.118 & -0.008 \\
\hline Other milk & 0.029 & -0.099 & 0.042 & -0.006 \\
\hline Infant formula & 0.059 & -0.011 & -0.058 & 0.080 \\
\hline Yoghurt & 0.100 & 0.234 & -0.201 & 0.219 \\
\hline Porridge and unsweetened cereals & 0.004 & 0.203 & $-0.351^{*}$ & 0.020 \\
\hline Sweet cereals & $0.336^{*}$ & 0.139 & -0.158 & 0.210 \\
\hline Semi- and whole-grain bread & -0.099 & 0.145 & $0.768^{*}$ & 0.153 \\
\hline White bread & 0.236 & 0.052 & 0.011 & -0.100 \\
\hline Butter/margarine & 0.147 & 0.112 & $0.676^{*}$ & -0.030 \\
\hline Cheese & -0.180 & 0.148 & $0.494^{*}$ & 0.100 \\
\hline Sweet spreads & 0.149 & -0.073 & $0.367^{\star}$ & 0.048 \\
\hline Eggs & 0.082 & 0.148 & 0.211 & 0.067 \\
\hline Fat spreads & 0.005 & 0.028 & 0.062 & 0.140 \\
\hline Meat & 0.140 & 0.234 & $0.574^{*}$ & 0.070 \\
\hline Sausages & $0.441^{*}$ & 0.039 & 0.231 & -0.064 \\
\hline Poultry & 0.059 & $0.300^{*}$ & 0.006 & 0.175 \\
\hline Fish & 0.055 & $0.459^{*}$ & 0.265 & 0.057 \\
\hline Tomato soup/other soup & 0.035 & 0.186 & -0.013 & 0.235 \\
\hline Pancakes & 0.075 & 0.180 & -0.036 & $0.378^{\star}$ \\
\hline Stew with meat, vegetables and potatoes & 0.134 & $0.328^{*}$ & 0.104 & -0.051 \\
\hline Rice porridge & 0.002 & 0.188 & 0.001 & 0.218 \\
\hline Pizza & $0.314^{*}$ & 0.029 & $0 \cdot 191$ & 0.264 \\
\hline Sauce & 0.233 & 0.278 & 0.200 & -0.290 \\
\hline Ketchup & $0.415^{\star}$ & -0.037 & 0.216 & 0.046 \\
\hline Rice & -0.049 & $0.468^{*}$ & -0.070 & 0.091 \\
\hline Pasta & -0.043 & $0.489^{*}$ & -0.032 & 0.064 \\
\hline Potatoes & 0.126 & $0.591^{*}$ & 0.149 & -0.265 \\
\hline Fried potatoes & $0.330^{*}$ & 0.157 & -0.034 & 0.037 \\
\hline Hamburger buns & $0.351^{*}$ & 0.032 & 0.050 & 0.287 \\
\hline Vegetables & 0.009 & $0.653^{*}$ & 0.028 & -0.096 \\
\hline Commercial baby food & 0.112 & 0.006 & -0.015 & -0.220 \\
\hline Ice-cream and pudding & $0.453^{*}$ & 0.010 & -0.001 & 0.071 \\
\hline Cakes and biscuits & $0.376^{*}$ & 0.124 & 0.079 & 0.171 \\
\hline Sweets & $0.614^{*}$ & -0.141 & 0.059 & 0.007 \\
\hline Salty snacks & $0.557^{*}$ & 0.005 & 0.082 & -0.112 \\
\hline Fruits and berries & -0.095 & $0.490^{*}$ & 0.079 & $0.306^{*}$ \\
\hline Dried fruits & 0.034 & 0.234 & -0.075 & 0.123 \\
\hline Sugar-sweetened drinks & $0.474^{\star}$ & 0.019 & -0.028 & -0.016 \\
\hline Artificially sweetened drinks & 0.290 & -0.101 & -0.016 & -0.048 \\
\hline Fruit juice & 0.070 & 0.097 & -0.092 & 0.263 \\
\hline Rosehip syrup & -0.060 & 0.039 & -0.092 & 0.003 \\
\hline Water & -0.158 & $0.335^{*}$ & 0.132 & 0.052 \\
\hline Sugar & 0.157 & 0.096 & -0.205 & 0.139 \\
\hline Herb tea & 0.026 & 0.037 & -0.051 & 0.044 \\
\hline
\end{tabular}

* Loadings $\geq 0.3$ or $\leq-0.3$.

lowest mean scores were observed among the 2-year-olds whose mothers were on leave.

Children of smoking mothers (2007 data) had a significantly higher mean score for the 'unhealthy' and the 'traditional' patterns compared with those of non-smoking mothers. Without adjustment for maternal smoking in the 2007 data, the associations between the 'traditional' pattern and maternal education was significant $(\beta=-0.13(95 \%$ CI $-0.26,-0.003)$ and $\beta=-0.19 \quad(95 \%$ CI -0.34 , $-0 \cdot 04)$ ). Other mean scores without adjustment for maternal smoking showed only minor differences compared with the presented values in Table 5.

Higher maternal and paternal educational levels were significantly associated with lower mean scores for the 'unhealthy' pattern and higher scores for the 'low-fat milk, pancakes, fruits and berries' pattern in 1999. In 2007, as paternal educational level increased, the mean score for the 'healthy' pattern significantly increased. Higher maternal education was significantly associated with lower mean scores for the 'baby food' pattern in 2007. Paternal education was also significantly associated with the 'baby food' pattern; however, there was no clear direction with regard to this association.

\section{Discussion}

Based on data from two large national dietary surveys among 2-year-olds in Norway in 1999 and 2007, four dietary patterns 
Table 3. Factor loadings of food groups in the four dietary patterns identified, together with the explained variance in percentage, in 2-year-old children in the 2007 data ( $n$ 1472)

\begin{tabular}{|c|c|c|c|c|}
\hline & $\begin{array}{c}\text { Unhealthy } \\
5.6 \%\end{array}$ & $\begin{array}{c}\text { Traditional } \\
5.1 \%\end{array}$ & $\begin{array}{c}\text { Healthy } \\
4.7 \%\end{array}$ & $\begin{array}{c}\text { Baby fooc } \\
4.2 \%\end{array}$ \\
\hline Full-fat milk & 0.012 & 0.050 & -0.094 & 0.241 \\
\hline Low-fat milk & -0.026 & 0.023 & 0.048 & -0.261 \\
\hline Chocolate milk & 0.207 & 0.057 & -0.037 & 0.257 \\
\hline Other milk & -0.094 & 0.135 & -0.030 & 0.102 \\
\hline Infant formula & -0.057 & -0.010 & -0.009 & 0.173 \\
\hline Yoghurt & 0.016 & -0.062 & 0.245 & 0.122 \\
\hline Porridge and unsweetened cereals & -0.191 & 0.025 & 0.181 & $0.562^{*}$ \\
\hline Sweet cereals & 0.235 & -0.116 & 0.247 & 0.133 \\
\hline Semi- and whole-grain bread & -0.020 & $0.495^{\star}$ & 0.046 & $-0.511^{*}$ \\
\hline White bread & 0.214 & 0.035 & -0.041 & 0.009 \\
\hline Butter/margarine & 0.135 & $0.510^{*}$ & -0.131 & -0.245 \\
\hline Cheese & -0.048 & 0.275 & 0.079 & $-0.380^{*}$ \\
\hline Sweet spreads & 0.244 & 0.250 & -0.027 & 0.002 \\
\hline Eggs & -0.084 & $0.354^{*}$ & 0.110 & 0.016 \\
\hline Fat spreads & 0.034 & $0 \cdot 110$ & -0.037 & -0.005 \\
\hline Meat & $0 \cdot 102$ & $0.580^{*}$ & 0.114 & -0.285 \\
\hline Sausages & 0.187 & 0.103 & 0.257 & -0.277 \\
\hline Poultry & -0.032 & 0.123 & $0.305^{*}$ & -0.150 \\
\hline Fish & -0.108 & $0.485^{\star}$ & $0.301^{*}$ & -0.042 \\
\hline Tomato soup/other soup & 0.045 & 0.008 & $0.344^{*}$ & 0.026 \\
\hline Pancakes & 0.220 & -0.053 & $0.458^{*}$ & -0.145 \\
\hline Stew with meat, vegetables and potatoes & 0.050 & $0.411^{*}$ & 0.189 & 0.137 \\
\hline Rice porridge & 0.106 & 0.053 & 0.269 & 0.030 \\
\hline Pizza & $0.361^{*}$ & -0.001 & $0.343^{*}$ & -0.192 \\
\hline Sauce & 0.118 & $0.459^{*}$ & -0.111 & 0.187 \\
\hline Ketchup & $0.417^{\star}$ & -0.015 & 0.114 & -0.143 \\
\hline Rice & 0.021 & -0.036 & $0.475^{\star}$ & -0.087 \\
\hline Pasta & 0.021 & -0.007 & $0.522^{*}$ & -0.117 \\
\hline Potatoes & 0.096 & $0.524^{*}$ & 0.067 & 0.129 \\
\hline Fried potatoes & $0.390^{*}$ & -0.021 & $0 \cdot 161$ & -0.054 \\
\hline Hamburger buns & $0.342^{*}$ & -0.022 & $0 \cdot 165$ & -0.016 \\
\hline Vegetables & -0.155 & $0.411^{*}$ & $0.391^{\star}$ & 0.127 \\
\hline Commercial baby food & -0.069 & 0.088 & -0.067 & $0.399^{*}$ \\
\hline Ice-cream and pudding & $0.487^{*}$ & 0.012 & 0.009 & 0.202 \\
\hline Cakes and biscuits & $0.371^{*}$ & 0.046 & $0.306^{*}$ & $0 \cdot 106$ \\
\hline Sweets & $0.659^{*}$ & 0.006 & -0.060 & -0.009 \\
\hline Salty snacks & $0.625^{\star}$ & 0.057 & -0.082 & -0.008 \\
\hline Fruits and berries & -0.046 & 0.250 & $0.346^{*}$ & 0.117 \\
\hline Dried fruits & -0.013 & 0.108 & 0.250 & 0.252 \\
\hline Sugar-sweetened drinks & $0.458^{*}$ & 0.096 & -0.203 & 0.199 \\
\hline Artificially sweetened drinks & 0.288 & 0.009 & 0.044 & -0.050 \\
\hline Fruit juice & 0.219 & 0.063 & 0.075 & 0.241 \\
\hline Rosehip syrup & 0.056 & -0.002 & 0.142 & 0.195 \\
\hline Water & -0.057 & 0.205 & $0.312^{*}$ & -0.096 \\
\hline Sugar & 0.149 & 0.056 & 0.093 & $0.346^{*}$ \\
\hline Canned fruit & 0.059 & 0.085 & 0.081 & 0.085 \\
\hline Sour cream & -0.055 & 0.081 & 0.099 & 0.050 \\
\hline
\end{tabular}

* Loadings $\geq 0.3$ or $\leq-0.3$.

were identified each year. The 'unhealthy' patterns in 1999 and in 2007 were similar with regard to loadings of food groups; moreover, these patterns were at both time points associated with sex, breastfeeding at 12 months of age, parity, maternal age and maternal work situation. A positive relationship between the 'healthy' pattern and paternal education was found in the 2007 data.

\section{Dietary patterns}

Even if dietary patterns might be population specific, most studies of preschool children using PCA or cluster analysis have identified a type of healthy, unhealthy and traditional pattern $^{(7)}$. This is in line with the findings in the present study.

In the Norwegian Mother and Child Cohort Study (MoBa), an 'unhealthy' and a 'wholesome' dietary pattern among both 18-month-old and 3-year-old children have been found ${ }^{(13,20)}$. These patterns are comparable with the 'unhealthy' and 'healthy' patterns derived in the present study, as 'unhealthy' patterns were characterised by fatty and sugary food items, while the 'wholesome' or 'healthy' patterns included fish, rice, pasta, vegetables and fruits. The FFQ used in the MoBa include less than forty food items, and this may explain why only two patterns were derived in the MoBa study compared with four patterns derived at each time point in the present study. 
Table 4. Adjusted mean scores for each dietary pattern, and their associations with child and parent characteristics (each dietary pattern is adjusted for all the presented characteristics including geographical region) in the 1999 data ( $n$ 1373)

(Mean values and $95 \%$ confidence intervals)

\begin{tabular}{|c|c|c|c|c|c|c|c|c|}
\hline \multirow[b]{2}{*}{ Child and parent characteristics } & \multicolumn{2}{|r|}{ Unhealthy } & \multicolumn{2}{|r|}{ Healthy } & \multicolumn{2}{|c|}{ Bread and spread-based } & \multicolumn{2}{|c|}{$\begin{array}{l}\text { Low-fat milk, pancakes, } \\
\text { fruits and berries }\end{array}$} \\
\hline & Mean & $95 \% \mathrm{Cl}$ & Mean & $95 \% \mathrm{Cl}$ & Mean & $95 \% \mathrm{Cl}$ & Mean & $95 \% \mathrm{Cl}$ \\
\hline \multicolumn{9}{|l|}{ Sex } \\
\hline Boys ( $n$ 687) & \multicolumn{2}{|r|}{0} & \multicolumn{2}{|r|}{0} & \multicolumn{2}{|r|}{0} & \multicolumn{2}{|r|}{0} \\
\hline Girls ( $n$ 686) & -0.14 & $-0.24,-0.04$ & -0.15 & $-0.26,-0.04$ & -0.17 & $-0.28,-0.07$ & -0.14 & $-0.24,-0.03$ \\
\hline$P$ & \multicolumn{2}{|r|}{0.008} & \multicolumn{2}{|r|}{0.006} & \multicolumn{2}{|r|}{0.001} & \multicolumn{2}{|r|}{0.010} \\
\hline \multicolumn{9}{|l|}{ Breastfed at 12 months of age } \\
\hline No $(n 929)$ & \multirow{3}{*}{$-0 \cdot 17$} & 0 & \multicolumn{2}{|r|}{0} & \multicolumn{2}{|r|}{0} & \multirow{3}{*}{\multicolumn{2}{|c|}{$\begin{array}{l}0 \\
-0.08,0.22 \\
0.068\end{array}$}} \\
\hline Yes $(n 444)$ & & $-0.28,-0.06$ & 0.05 & $-0.07,0.17$ & -0.10 & $-0.21,0.02$ & & \\
\hline$P$ & & 0.002 & & 0.432 & & 0.102 & & \\
\hline \multicolumn{9}{|l|}{ Parity } \\
\hline One child ( $n$ 447) & \multicolumn{2}{|r|}{0} & \multicolumn{2}{|r|}{0} & \multicolumn{2}{|r|}{0} & \multicolumn{2}{|r|}{0} \\
\hline Two children ( $n$ 575) & 0.25 & $0.13,0.38$ & -0.06 & $-0.19,0.07$ & 0.18 & $0.05,0.31$ & 0.18 & $0.05,0.30$ \\
\hline$\geq$ Three children ( $n$ 351) & 0.27 & $0.12,0.42$ & -0.16 & $-0.32,0.002$ & 0.14 & $-0.02,0.30$ & 0.35 & $0.19,0.51$ \\
\hline$P$ & & $<0.0001$ & & 0.152 & & 0.023 & & $<0.0001$ \\
\hline Maternal age & & & & & & & & \\
\hline$\leq 24$ years $(n 114)$ & & 0 & & 0 & & 0 & & 0 \\
\hline $25-34$ years $(n 971)$ & -0.40 & $-0.60,-0.20$ & -0.07 & $-0.28,0.15$ & -0.11 & $-0.32,0.11$ & -0.20 & $-0.41,0.005$ \\
\hline$\geq 35$ years $(n 288)$ & -0.48 & $-0.72,-0.25$ & -0.07 & $-0.32,0.19$ & -0.31 & $-0.56,-0.07$ & -0.26 & $-0.51,-0.02$ \\
\hline$P$ & & $<0.0001$ & & 0.826 & & 0.008 & & 0.101 \\
\hline Maternal marital status & & & & & & & & \\
\hline Married/cohabitant ( $n$ 1316) & & 0 & & 0 & & 0 & & 0 \\
\hline Not married/cohabitant ( $n$ 57) & 0.06 & $-0.21,0.32$ & 0.07 & $-0.21,0.35$ & 0.04 & $-0.24,0.31$ & 0.03 & $-0.24,0.30$ \\
\hline$P$ & & 0.675 & & 0.605 & & 0.780 & & 0.842 \\
\hline Maternal work situation now & & & & & & & & \\
\hline Full-time ( $n$ 386) & & 0 & & 0 & & 0 & & 0 \\
\hline Part-time ( $n$ 448) & 0.12 & $-0.02,0.25$ & 0.02 & $-0.13,0.16$ & -0.10 & $-0.24,0.04$ & -0.05 & $-0.19,0.09$ \\
\hline On leave $(n 141)$ & -0.07 & $-0.25,0.12$ & 0.13 & $-0.08,0.33$ & -0.15 & $-0.35,0.05$ & -0.18 & $-0.38,0.01$ \\
\hline Other $^{*}(n 398)$ & 0.15 & $0.01,0.29$ & 0.03 & $-0.12,0.19$ & -0.23 & $-0.38,-0.08$ & -0.02 & $-0.17,0.12$ \\
\hline$P$ & & 0.036 & & 0.656 & & 0.024 & & 0.308 \\
\hline Maternal education & & & & & & & & \\
\hline Primary, secondary school and comprehensive school ( $n 681)$ & & 0 & & 0 & & 0 & & 0 \\
\hline Academy/college/university ( $\leq 4$ years) $(n 461)$ & -0.14 & $-0.26,-0.01$ & -0.07 & $-0.20,0.07$ & -0.11 & $-0.24,0.02$ & 0.14 & $0.02,0.27$ \\
\hline Academy/college/university ( $>4$ years) ( $n 231$ ) & -0.32 & $-0.49,-0.14$ & -0.17 & $-0.36,0.02$ & -0.11 & $-0.29,0.07$ & 0.26 & $0.08,0.44$ \\
\hline$P$ & & 0.001 & & 0.197 & & 0.208 & & 0.010 \\
\hline Paternal education & & & & & & & & \\
\hline Primary, secondary school and comprehensive school ( $n 744)$ & & 0 & & 0 & & 0 & & 0 \\
\hline Academy/college/university ( $\leq 4$ years) $(n 339)$ & -0.21 & $-0.34,-0.08$ & 0.17 & $0.00,0.33$ & -0.09 & $-0.23,0.05$ & $0 \cdot 11$ & $-0.03,0.24$ \\
\hline Academy/college/university ( $>4$ years) ( $n$ 290) & -0.33 & $-0.49,-0.18$ & 0.09 & $-0.05,0.23$ & 0.06 & $-0.10,0.23$ & 0.20 & $0.04,0.36$ \\
\hline$P$ & & $<0.0001$ & & 0.131 & & 0.179 & & 0.042 \\
\hline
\end{tabular}

${ }^{*}$ Including mothers working at home/housewives, mothers on sick leave, unemployed, disabled, occupational rehabilitation, student or other work situations. 
Table 5. Adjusted mean scores for each dietary pattern, and their associations with child and parent characteristics (each dietary pattern is adjusted for all the presented characteristics including geographical region) in the 2007 data ( $n$ 1472)

(Mean values and $95 \%$ confidence intervals)

\begin{tabular}{|c|c|c|c|c|c|c|c|c|}
\hline \multirow[b]{2}{*}{ Child and parent characteristics } & \multicolumn{2}{|r|}{ Unhealthy } & \multicolumn{2}{|r|}{ Traditional } & \multicolumn{2}{|r|}{ Healthy } & \multicolumn{2}{|r|}{ Baby food } \\
\hline & Mean & $95 \% \mathrm{Cl}$ & Mean & $95 \% \mathrm{Cl}$ & Mean & $95 \% \mathrm{Cl}$ & Mean & $95 \% \mathrm{Cl}$ \\
\hline \multicolumn{9}{|l|}{ Sex } \\
\hline Boys ( $n$ 718) & \multicolumn{2}{|r|}{0} & \multicolumn{2}{|r|}{0} & \multicolumn{2}{|r|}{0} & \multicolumn{2}{|r|}{0} \\
\hline Girls $(n 754)$ & $-0 \cdot 11$ & $-0.21,-0.01$ & $-0 \cdot 15$ & $-0.25,-0.05$ & -0.06 & $-0.16,0.04$ & -0.01 & $-0.11,0.09$ \\
\hline & & 0.028 & & 0.003 & & 0.230 & & 0.874 \\
\hline \multicolumn{9}{|l|}{ Breastfed at 12 months of age } \\
\hline No $(n$ 1018) & \multicolumn{2}{|r|}{0} & \multicolumn{2}{|r|}{0} & \multicolumn{2}{|r|}{0} & \multicolumn{2}{|r|}{0} \\
\hline Yes $(n 454)$ & -0.14 & $-0.25,-0.04$ & -0.07 & $-0.19,0.04$ & -0.01 & $-0.12,0.10$ & -0.004 & $-0.11,0.12$ \\
\hline$P$ & \multicolumn{2}{|r|}{0.009} & \multicolumn{2}{|r|}{0.200} & \multicolumn{2}{|r|}{0.852} & \multicolumn{2}{|r|}{0.940} \\
\hline \multicolumn{9}{|l|}{ Parity } \\
\hline One child ( $n$ 553) & \multicolumn{2}{|r|}{0} & \multicolumn{2}{|r|}{0} & \multicolumn{2}{|r|}{0} & & 0 \\
\hline Two children ( $n$ 593) & 0.52 & $0.41,0.64$ & -0.08 & $-0.20,0.42$ & 0.07 & $-0.05,0.19$ & -0.19 & $-0.31,-0.08$ \\
\hline$\geq$ Three children ( $n$ 326) & 0.68 & $0.53,0.82$ & -0.04 & $-0.19,0.11$ & -0.01 & $-0.16,0.14$ & -0.11 & $-0.26,0.04$ \\
\hline$P$ & & $<0.0001$ & & 0.448 & & 0.430 & & 0.006 \\
\hline Maternal age & & & & & & & & \\
\hline$\leq 24$ years $(n 80)$ & & 0 & & 0 & & 0 & & 0 \\
\hline $25-34$ years $(n 906)$ & -0.12 & $-0.35,0.11$ & $0 \cdot 19$ & $-0.05,0.43$ & -0.12 & $-0.36,0.12$ & 0.20 & $-0.04,0.44$ \\
\hline$\geq 35$ years $(n 486)$ & -0.27 & $-0.51,-0.02$ & 0.13 & $-0.12,0.39$ & -0.21 & $-0.47,0.04$ & 0.33 & $0.07,0.58$ \\
\hline$P$ & & 0.016 & & 0.210 & & 0.145 & & 0.017 \\
\hline Maternal marital status & & & & & & & & \\
\hline Married/cohabitant ( $n$ 1419) & & 0 & & 0 & & 0 & & 0 \\
\hline Not married/cohabitant ( $n 53)$ & 0.03 & $-0.23,0.30$ & 0.14 & $-0.14,0.41$ & -0.15 & $-0.43,0.13$ & 0.23 & $-0.05,0.50$ \\
\hline$P$ & & 0.809 & & 0.332 & & 0.288 & & 0.109 \\
\hline Maternal work situation now & & & & & & & & \\
\hline Full-time ( $n$ 623) & & 0 & & 0 & & 0 & & 0 \\
\hline Part-time ( $n$ 432) & 0.03 & $-0.09,0.15$ & 0.02 & $-0.11,0.15$ & -0.15 & $-0.27,-0.02$ & $0 \cdot 18$ & $0.06,0.31$ \\
\hline On leave ( $n$ 155) & -0.24 & $-0.41,-0.06$ & -0.03 & $-0.21,0.15$ & 0.02 & $-0.16,0.20$ & 0.48 & $0.30,0.66$ \\
\hline Other $^{*}(n$ 262) & 0.08 & $-0.07,0.22$ & -0.06 & $-0.21,0.08$ & -0.03 & $-0.18,0.12$ & 0.34 & $0.19,0.49$ \\
\hline$P$ & & 0.010 & & 0.737 & & 0.095 & & $<0.0001$ \\
\hline Maternal smoking & & & & & & & & \\
\hline Non-smoker ( $n$ 1207) & & 0 & & 0 & & 0 & & 0 \\
\hline Smoker $(n 265)$ & 0.16 & $0.03,0.30$ & 0.25 & $0.11,0.39$ & 0.002 & $-0.14,0.14$ & 0.06 & $-0.08,0.20$ \\
\hline$P$ & & 0.018 & & $<0.0001$ & & 0.981 & & 0.370 \\
\hline Maternal education & & & & & & & & \\
\hline Primary, secondary school and comprehensive school ( $n$ 534) & & 0 & & 0 & & 0 & & 0 \\
\hline Academy/college/university ( $\leq 4$ years) $(n 530)$ & -0.06 & $-0.19,0.07$ & $-0 \cdot 10$ & $-0.23,0.04$ & 0.06 & $-0.07,0.19$ & -0.13 & $-0.26,0.00$ \\
\hline Academy/college/university ( $>4$ years) $(n 408)$ & -0.09 & $-0.24,0.06$ & -0.15 & $-0.30,0.01$ & 0.15 & $-0.003,0.30$ & -0.21 & $-0.36,-0.06$ \\
\hline$P$ & & 0.486 & & 0.155 & & 0.152 & & 0.023 \\
\hline Paternal education & & & & & & & & \\
\hline Primary, secondary school and comprehensive school ( $n$ 754) & & 0 & & 0 & & 0 & & 0 \\
\hline Academy/college/university ( $\leq 4$ years) $(n 350)$ & -0.07 & $-0.20,0.06$ & 0.01 & $-0.13,0.14$ & 0.14 & $0.01,0.27$ & -0.15 & $-0.29,-0.02$ \\
\hline Academy/college/university ( $>4$ years) $(n 368)$ & -0.13 & $-0.27,0.01$ & -0.13 & $-0.28,0.01$ & 0.19 & $0.05,0.34$ & 0.05 & $-0 \cdot 10,0 \cdot 19$ \\
\hline$P$ & & 0.167 & & 0.141 & & 0.019 & & 0.020 \\
\hline
\end{tabular}

*Including mothers working at home/housewives, mothers on sick leave, unemployed, disabled, occupational rehabilitation, student or other work situations. 


\section{Associations with the 'healthy' and the 'unhealthy' patterns}

Among adults, higher education, age and income have often been reported to be associated with more healthy dietary patterns ${ }^{(6,21)}$. While healthier eating habits among preschool children have been associated with higher maternal education and/or age $\mathrm{e}^{(3,10,11,13)}$, we found a positive relationship between the 'healthy' pattern and paternal education in the 2007 data. No association was seen between parental education and the 'healthy' pattern in the 1999 data. Surprisingly, girls had significantly lower scores on the 'healthy' pattern than boys in 1999. This is in contrast to what was identified among the 18-month-old children in the MoBa study ${ }^{(13)}$ and 3-year-olds participating at the large prospective birth cohort, the Avon Longitudinal Study of Parents and Children (the ALSPAC study) ${ }^{(10)}$.

Girls had significantly lower scores than boys for the 'unhealthy' pattern in both 1999 and 2007. This finding is supported by the results among the 4- and 7-year-olds in the ALSPAC study, showing that girls had a lower mean score for the 'junk' pattern compared with boys ${ }^{(11)}$. The 'unhealthy' pattern was, at both time points, negatively associated with maternal age and positively associated with number of children. These associations are in line with those found with the 'junk' pattern in the ALSPAC study ${ }^{(10,11)}$, the 'unhealthy' pattern among the 18-month-olds in the MoBa study ${ }^{(13)}$ and the 'adult food' pattern (characterised by high loadings for white bread, savoury snacks, biscuits and chips) among the 12-month-olds in the Southampton Women's Survey study cohort $^{(3)}$. In our data from 1999, negative associations were also seen between increasing parental education and the 'unhealthy' pattern.

In the data from 1999 and 2007, those breastfed at 12 months of age had a significantly lower mean score for the 'unhealthy' pattern. In the Southampton Women's Survey study, a similar association was seen among the 12-montholds, where the dietary pattern labelled 'adult foods' was inversely associated with intake of breast milk ${ }^{(3)}$. We did not find a positive association between the 'healthy' patterns and breastfeeding in the present study, while such an association was found in a study including a national sample of 2287 Australian 2- to 8-year-old children ${ }^{(22)}$.

A positive association between maternal smoking and a type of unhealthy dietary pattern among preschool children has been observed by others ${ }^{(3,10,13)}$. A similar association was seen in the 2007 data of the present study.

The associations between maternal work situation and the 'unhealthy' pattern observed at the two time points are difficult to compare with findings from other studies, as maternal work situation is differently categorised. In the ALSPAC study ${ }^{(10,11)}$, children of employed mothers had a significantly higher mean score for the 'junk' pattern compared with unemployed mothers.

\section{Associations with other dietary patterns}

For the 'bread and spread-based' pattern in 1999 and the 'traditional' pattern in 2007, a significantly lower mean score was observed for girls compared with boys. In the ALSPAC study, boys had a significantly lower mean score for the 'traditional' pattern compared with girls ${ }^{(10,11)}$. We observed a significantly higher mean score for the 'traditional' pattern among 2-yearolds of smoking mothers compared with those of non-smoking mothers in 2007. This was also seen among the 3-year-olds in the ALSPAC study ${ }^{(10)}$.

The mean score for the low-fat milk, pancakes, fruits and berries' pattern significantly increased with parity and the level of parental education; in addition, girls had a significantly lower score for this pattern compared with boys. This pattern had negative loadings for full-fat milk, suggesting a type of health consciousness reflected by this pattern as well. The most comparable pattern with the 'baby food' pattern in 2007 is the 'baby jar' pattern observed among the 6-month-old infants in the Southampton Women's Survey study $^{(3)}$, where an independent, yet small, association was only found with maternal age.

\section{Strengths and limitations}

Strengths of the present study are the use of validated SFFQ covering a wide range of food items, including portion size on all food items, and the recall period according to dietary habits was short, as parents were asked to keep the last $14 \mathrm{~d}$ in mind. Data on breastfeeding were also collected retrospectively, within a maximum of 24 months after termination. According to Li et al. ${ }^{(23)}$ the recall of breastfeeding can be expected to be reliable, as the recall period is shorter than 3 years. Of course, we cannot fully exclude recall error with regard to dietary habits or breastfeeding.

Differences in patterns, loadings in patterns and associations between patterns and child and parent characteristics at the two time points may be due to the significant differences between the populations participating in the study in 1999 and in 2007, which might reflect the differences between the general population in Norway in 2007 and that of $1999^{(14,15)}$ In six out of eight patterns in the present study, girls had a significantly lower mean score compared with boys. This may be caused by girls consuming less food compared with boys, and that the present analysis has been driven by the volume of food intake per d. Moreover, the study of 1999 was conducted during the winter/spring months, while the study of 2007 was conducted during autumn. However, except for oranges, there are no reasons to believe that seasonality has contributed to the differences, as the food items asked about in the two questionnaires are available all through the year in Norway. We cannot exclude the possibility that the reported intake of food items in 1999 and in 2007 are affected by the differences in the questionnaires used at each time point ${ }^{(18)}$.

We chose to present data unadjusted for energy intake. When the data were analysed with energy adjustment, the Kaiser-Meyer-Olkin was close to zero (less than 0.03). Even if the correlation between maternal and paternal 
education was $0 \cdot 5$, we chose to include both maternal and paternal educational level in the analysis, as these variables may represent different influences on the dietary patterns of the 2-year-olds.

In conclusion, four dietary patterns were identified in 1999 and in 2007. The 'unhealthy' patterns identified in both years were similar with regard to loadings of food groups and were, at both time points, associated with sex, breastfeeding at 12 months of age, parity, maternal age and maternal work situation.

\section{Supplementary material}

To view supplementary material for this article, please visit http://dx.doi.org/10.1017/S0007114512004643

\section{Acknowledgements}

This project has been financially supported by the Norwegian ExtraFoundation for Health and Rehabilitation through EXTRA funds. The authors declare no conflict of interest. A. L. K. carried out the data analyses and wrote the manuscript; B. L., J. A. S. and L. F. A. assisted and provided advice during all the stages of the work. All authors contributed in the discussion and interpretation of the results, and in the drafting and editing of the manuscript. The authors are grateful to all children and their parents who participated in the national dietary surveys in 1999 and in 2007.

\section{References}

1. Ip S, Chung M, Raman G, et al. (2007) Breastfeeding and maternal and infant health outcomes in developed countries. Evid Rep Technol Assess (Full Rep) 153, 1-186.

2. Northstone K \& Emmett PM (2008) Are dietary patterns stable throughout early and mid-childhood? A birth cohort study. Br J Nutr 100, 1069-1076.

3. Robinson S, Marriott L, Poole J, et al. (2007) Dietary patterns in infancy: the importance of maternal and family influences on feeding practice. Br J Nutr 98, 1029-1037.

4. Hu FB (2002) Dietary pattern analysis: a new direction in nutritional epidemiology. Curr Opin Lipidol 13, 3-9.

5. Michels KB \& Schulze MB (2005) Can dietary patterns help us detect diet-disease associations? Nutr Res Rev 18, 241-248

6. Newby PK \& Tucker KL (2004) Empirically derived eating patterns using factor or cluster analysis: a review. Nutr Rev 62, 177-203.

7. Smithers LG, Golley RK, Brazionis L, et al. (2011) Characterizing whole diets of young children from developed countries and the association between diet and health: a systematic review. Nutr Rev 69, 449-467.

8. Smith AD, Emmett PM, Newby PK, et al. (2011) A comparison of dietary patterns derived by cluster and principal components analysis in a UK cohort of children. Eur J Clin Nutr 65, 1102-1109.

9. Friedman LS, Lukyanova EM, Serdiuk A, et al. (2009) Socialenvironmental factors associated with elevated body mass index in a Ukrainian cohort of children. Int J Pediatr Obes 4, 81-90.

10. North K \& Emmett P (2000) Multivariate analysis of diet among three-year-old children and associations with sociodemographic characteristics. The Avon Longitudinal Study of Pregnancy and Childhood (ALSPAC) Study Team. Eur J Clin Nutr 54, 73-80.

11. Northstone K \& Emmett P (2005) Multivariate analysis of diet in children at four and seven years of age and associations with socio-demographic characteristics. Eur J Clin Nutr 59, 751-760.

12. Shin KO, Oh SY \& Park HS (2007) Empirically derived major dietary patterns and their associations with overweight in Korean preschool children. Br J Nutr 98, 416-421.

13. Ystrom E, Niegel S \& Vollrath ME (2009) The impact of maternal negative affectivity on dietary patterns of 18-month-old children in the Norwegian Mother and Child Cohort Study. Matern Child Nutr 5, 234-242.

14. Lande B \& Andersen LF (2005) Småbarnskost 1999 Dietary Habits Among 2-year-old Children in Norway (in Norwegian). Report no. IS-1299. Oslo: Norwegian Directorate of Health.

15. Kristiansen AL, Andersen LF \& Lande B (2009) Småbarnskost 2007 - Dietary Habits Among 2-year-old Children in Norway (in Norwegian). Report no. IS-1731. Oslo: Norwegian Directorate of Health.

16. Andersen LF, Lande B, Trygg K, et al. (2004) Validation of a semi-quantitative food-frequency questionnaire used among 2-year-old Norwegian children. Public Health Nutr 7, $757-764$.

17. Slettahjell HB (2008) Validation of a semi-quantitative food frequency questionnaire used among 1.5- to 3-year-old Norwegian children. Masters Thesis, Department of Nutrition, Institute of Basic Medical Science, University of Oslo.

18. Kristiansen AL, Lillegaard IT, Lande B, et al. (2012) Effect of changes in an FFQ: comparing data from two national dietary survey instruments among 2-year-olds. $\mathrm{Br} J \mathrm{Nutr}$ (Epublication ahead of print version 4 May 2012).

19. Tabachnick BG \& Fidell LS (2007) Using Multivariate Statistics, 5th ed., Chapter 13. Boston, MA: Pearson Education.

20. Ystrom E, Barker M \& Vollrath ME (2012) Impact of mothers' negative affectivity, parental locus of control and childfeeding practices on dietary patterns of 3-year-old children: the MoBa Cohort Study. Matern Child Nutr 8, 103-114.

21. Kant AK (2004) Dietary patterns and health outcomes. J Am Diet Assoc 104, 615-635.

22. Grieger JA, Scott J \& Cobiac L (2011) Dietary patterns and breast-feeding in Australian children. Public Health Nutr 14, 1939-1947.

23. Li R, Scanlon KS \& Serdula MK (2005) The validity and reliability of maternal recall of breastfeeding practice. Nutr Rev 63, 103-110. 